\title{
Cubic differential systems with 2-invariant straight lines
}

\section{DUMitRu COZMA}

\section{ABSTRACT.}

For cubic differential system with a singular point $O(0,0)$ of a center or a focus type having three invariant straight lines of which one is 2-invariant it is proved that the origin is a center if and only if the first five Lyapunov quantities vanish.

Acknowledgements. This research was supported by FP7-PEOPLE-2012-IRSES-316338.

\section{REFERENCES}

[1] Christopher, C. and Llibre, J., Integrability via invariant algebraic curves for planar polynomial differential systems, Ann. Differential Equations, 16 (2000), No. 1, 5-19

[2] Cozma, D. and Şubă, A., Conditions for the existence of four invariant straight lines in a cubic differential systems with a singular point of a center or a focus type, Bull. Acad. Sci. of Moldova, Mathematics, 3 (1993), 54-62

[3] Cozma, D. and Şubă, A., Partial integrals and the first focal value in the problem of centre, Nonlinear Differ. Equ. and Appl., 2 (1995), 21-34

[4] Cozma, D. and Şubă, A., The solution of the problem of center for cubic differential systems with four invariant straight lines, Sci. Annals of the "Al. I. Cuza" University, Mathematics, vol. XLIV (1998), s.I.a, 517-530

[5] Cozma, D. and Şubă, A., Solution of the problem of the centre for a cubic differential system with three invariant straight lines, Qual. Theory Dyn. Syst., 2 (2001), 129-143

[6] Ljubimova, R. A., About one differential equation with invariant straight lines, In.: Diff. i Integr. Uravneniya, Gorky, 1977, 19-22; Gorky, 1984, 66-69 (in Russian)

[7] Llibre, J. and Vulpe, N., Planar cubic polynomial differential systems with the maximum number of invariant straight lines, Rocky Mountain J. Math., 36 (2006), No. 4, 1301-1373

[8] Llibre, J., Mahdi, A. and Vulpe, N., Phase portraits and invariant straight lines of cubic polynomial vector fields having a quadratic rational first integral, Rocky Mountain J. Math., 41 (2011), No. 5, 1585-1629

[9] Puţuntică, V. and Şubă, A., The cubic differential system with six real invariant straight lines along three directions, Bull. Acad. Sci. of Moldova, Mathematics, 60 (2009), No. 2, 111-130

[10] Şubă, A., On the Liapunov quantities of two-dimensional autonomous system of differential equations with a critical point of centre or focus type, Bulletin of Baia Mare University, Math. and Infor., 13 (1998), No. 1-2, 153-170

[11] Şubă, A. and Cozma, D., Solution of the problem of the center for cubic systems with two homogeneous and one non-homogeneous invariant straight lines, Bull. Acad. Sci. of Moldova, Mathematics, 29 (1999), No. 1, 37-44

[12] Şubă, A. and Cozma, D., Solution of the problem of center for cubic differential systems with three invariant straight lines in generic position, Qual. Theory Dyn. Syst., 6 (2005), 45-58

[13] Şubă, A., Repeşco, V. and Puţuntică, V., Cubic systems with seven invariant straight lines of configuration (3, 3, 1), Bull. Acad. Sci. of Moldova, Mathematics, 69 (2012), No. 2, 81-98

Department of Physics, MATHEMatics AND Information TeChNOlOgies

TIRASPOL STATE UNIVERSITY

5 GH. IABLOCIKIN , MD2069 CHIŞINĂU, REPUBLIC OF MOLdOVA

E-mail address: dcozma@gmail.com

* Dedicated to Professor Emeritus Constantin Corduneanu on the occasion of his 85th birthday

Received: 01.10.2013; In revised form: 10.10.2013; Accepted: 13.10.2013

2010 Mathematics Subject Classification. 34C05.

Key words and phrases. Cubic differential systems, the problem of the center, invariant straight lines. 